\title{
Performance Analysis of Solar Autoclave for Rural Health Center
}

\author{
Asfafaw HaileSelassie Tesfay ${ }^{1,2^{*}}$, Ashenafi Kebedom Abriha ${ }^{1}$ and Endalkachew Minas ${ }^{1}$ \\ ${ }^{1}$ School of Mechanical and Industrial Engineering, Ethiopian Institute of Technology (EiT-M), \\ Mekelle University, Ethiopia \\ ${ }^{2}$ Institute of Energy, Mekelle University (*asfafaw.haileslassie@ mu.edu.et).
}

\begin{abstract}
Proper sterilization of reusable medical devices and surgical instruments are critical aspects of modern health care delivery system that can also directly affect the patients. In off grid health centers and health posts, solar autoclave can have great contribution to facilitate modern heath care delivery by sterilizing medical infected equipment and reduces associated health risks. This research has developed a solar thermal based autoclave and analyzed its performance. The numerical and experimental results have validated with standard sterilization techniques and show successful and efficient results. The laboratory and community trial of the autoclave achieved temperatures of about $145^{\circ} \mathrm{C}$ and it was maintained it for more than 20 minutes that complies the sterilization process and procedures that has proved by the sterilization monitoring techniques. The field trial of the system was an encouraging comment to promote the technology and disseminate the technology.
\end{abstract}

Keywords: Solar autoclave; Autoclave performance testing; Solar sterilization; Rural health post; Off grid sterilization.

\section{INTRODUCTION}

The energy poverty in developing countries is a challenge in the health sector to provide proper service and control the dissemination of disease because of infected medical appliances. In such environments, it is difficult to provide good healthcare. Furthermore, unsterilized medical devices can infect patients and diseases can spread throughout health cares (Sarah Trabia, 2012). The availability of medical devices such as medical sanity equipment and reliable clean energy to use the medical equipment's safely are main challenges in the developing world. Such difficulties are causing many people in these countries to be infected with different kinds of communicable diseases (Heuck et al., 1991).

Rural health centers in Ethiopia that serve for more than $85 \%$ of the total population experience similar challenges. There is significantly truncated infrastructure in the rural areas. In addition, the widely dispersed living style makes rural electrification a problem with the country's economic condition. Accordingly, the rural communities have low access to energy, both for subsistence and productive purposes, and rely almost entirely on biomass fuels (Samuel and Momona Ethiopian Journal of Science (MEJS), V10(2):163-179,2018 OCNCS, Mekelle University,ISSN:2220-184X Submitted on: 23-03-2015 
Getachew, 2014). Ethiopia, the second most populous country in sub-Saharan Africa, experiences a heavy burden of diseases mainly attributed to communicable infectious diseases. Shortage and high turnover of human resource and inadequacy of essential drugs and supplies have also contributed to the burden (Healthcare in Ethiopia). According to 2010 health and health-related indicators published by Federal Ministry of Health (FMoH, 2010) in Tigray state, in which this research is undertaken, has 14 hospitals, 170 health centers and 552 health posts (http://www.moh.gov.et/tigrayhb) that have low energy access. Solar energy is one of the abundant renewable resources that can be harnessed for various applications. This energy can be used to autoclave medical instruments and treat biomedical waste (Dravid et al., 2012). Steambased autoclave systems neutralize potentially infectious microorganisms localized on solid surfaces by exposing them to high-temperature pressurized steam (Oara et al., 2013). Sterilization and disinfection are of fundamental importance in any health care. Any effective sterilizing design must sterilize equipment with bacteria such as Bacillus subtilis spores and Bacillus stearothermophilus spores. It only requires 12 minutes to inactivate 100,000 spores of B stearothermophilus in saturated steam at $121^{\circ} \mathrm{C}$ and a minute for $1,000,000$ spores of $\mathrm{B}$ subtilis (Block, 2001).This is the widely acceptable and recommended to sterilize effectively any medical equipment. This paper deals with performance analysis of locally developed solar thermal powered autoclave in view of the widely accepted sterilization standard procedures. The autoclave is able to convert liquid water in the boiler into steam to sterilize the medical equipment. According to Block (2001), sterilization by steam under pressure is a universally applied practice except where penetration or heat and moisture damage is a problem. Steam sterilization equipment has wide variety of shapes and sizes in hospitals, clinics, microbiologic laboratories etc. Steam sterilization works better than other forms of sterilization because steam destroys most resistant bacteria spores with a brief exposure. Steam sterilization is thus the best option for a solar autoclave.

The solar autoclave is designed to use parabolic dish concentrator to focus solar radiation into the absorber (pressure can). The absorber is a pressure vessel made up of can and it serves as both absorber and sterilizer. Medical instruments have put inside sterilizer with required amount of water and positioned into the focal point of the parabolic dish concentrator. Concentrated solar radiation is directed into the absorber to heat water and produce saturated steam inside the sterilizer. The steam temperature and pressure have held constant for sterilization. 


\begin{tabular}{|c|c|}
\hline Symbols and abbreviation & Description \\
\hline $\mathrm{A}_{\mathrm{a}}$ & Apparent area \\
\hline $\mathrm{A}_{\mathrm{abs}}$ & Absorber area (bottom area of the pressure cocker). \\
\hline $\mathrm{A}_{\mathrm{t}}$ & Pressure cooker top surface area \\
\hline $\mathrm{A}_{\text {st }}$ & Area of pressure vessel \\
\hline $\mathrm{C}$ & Concentration ratio \\
\hline $\mathrm{c}_{1}$ & specific heat capacity of aluminum \\
\hline $\mathrm{c}_{\mathrm{pw}}$ & specific heat capacity of water \\
\hline Di & Internal diameter of pressure vessel \\
\hline Hfg & Enthalpy of evaporation \\
\hline $\mathrm{h}_{\mathrm{s}}$ & Steam convective heat transfer coefficient, $6000 \mathrm{~W} / \mathrm{m}^{2} \mathrm{k}$ \\
\hline $\mathrm{h}_{\mathrm{w}}$ & Wind convective heat transfer coefficient $\left(\mathrm{W} / \mathrm{m}^{2} . \mathrm{K}\right)$ \\
\hline $\mathrm{K}$ & Stainless steel conductive heat transfer coefficient, $15.1 \mathrm{~W} / \mathrm{m} . \mathrm{K}$ \\
\hline $\mathrm{L}$ & Pressure cooker thickness \\
\hline $\mathrm{L}$ & Height of the pressure cooker \\
\hline $\mathrm{m}_{\mathrm{s}}$ & mass of steam in $\mathrm{kg} / \mathrm{s}$ \\
\hline$\dot{\mathrm{m}}_{\mathrm{st}}$ & mass flow rate of steam \\
\hline $\mathrm{m}_{\mathrm{w}}$ & mass of water \\
\hline $\operatorname{Re}$ & Reynolds number \\
\hline $\mathrm{r}_{\mathrm{i}}$ & pressure cooker inner radius \\
\hline $\mathrm{r}_{\mathrm{o}}$ & pressure cooker outer radius \\
\hline $\mathrm{T}_{\mathrm{a}}$ & ambient temperature \\
\hline $\mathrm{T}_{\mathrm{s}}$ & steam temperature \\
\hline$\Delta \mathrm{t}$ & Time of sterilization \\
\hline$\dot{\mathrm{V}}_{\mathrm{st} @ 0.3 \text { bar or } 1 \text { bar }}$ & Volumetric flow rate of steam \\
\hline$\dot{\mathrm{u}}_{\mathrm{st}}$ & Steam flow velocity \\
\hline$\rho_{\mathrm{st}}$ & Density of steam \\
\hline$\theta_{\mathrm{s}}$ & acceptance angle \\
\hline$\mu_{s t}$ & Dynamic viscosity of steam \\
\hline
\end{tabular}

(C) CNCS, Mekelle University 


\section{METHODOLOGY AND MATERIALS}

The methods used include thermal analysis, modeling and simulation, prototype development and experimentation.

\subsection{Thermal Analysis}

This method is used to determine the total heat required for sterilization and associated losses. Heat collected from the sun is used to generate steam in a pressure vessel, which was later used to sterilize the medical equipment. $300 \mathrm{ml}$ of water was used and converted into steam. Stainless steel surgical kits having $0.32 \mathrm{~kg}$ weight were considered for the autoclave power estimation. Eight medical kits were considered as a load of sterilization and seven-liter size pressure cooker was considered in satisfying the demand of rural health clinic. Thermal analysis standard parameters for sterilization are given in table 1.

Table 1. Standard parameter value used for calculation (Block, 2001)

\begin{tabular}{|ll|}
\hline Parameters & Value \\
\hline Steam temperature & $121^{\circ} \mathrm{C}$ \\
\hline Ambient temperature & $21^{\circ} \mathrm{C}$ \\
\hline Sterilization time for one load & 30 minute \\
\hline Average daily wind speed of Mekelle & $5.2 \mathrm{~m} / \mathrm{s}$ \\
\hline Average daily solar radiation of Mekelle & $6.09 \mathrm{Wh} / \mathrm{m}^{2} / \mathrm{d}$ \\
\hline
\end{tabular}

\subsubsection{Pressure Vessel}

The power absorption of the pressure vessel together with its heat loss have considered in sizing the parabolic dish collector. The thermal power used by the pressure vessel depends on the quantity of water and the temperature of the sterilization. This thermal power was calculated using equation 1 and the required amount of steam was quantified by equation 2 . The overall thermal power required to evaporate the water is analyzed using equation 3 .

$$
\begin{array}{ll}
Q_{\text {required }}=\frac{Q}{\Delta t}=\frac{m_{i} c_{i} \Delta T+m_{p c} c_{p c} \Delta T_{p c}}{\Delta t} & \text { eq. } 1 \\
m_{s}=\frac{Q_{r e q}}{h_{f g}} & \text { eq. } 2 \\
Q_{w}=\frac{m_{w} C_{p w} \Delta T}{\Delta t} & \text { eq. } 3
\end{array}
$$




\subsubsection{System Heat Losses}

The heat losses are generally from the lead, sidewall and bottom surfaces of the pressure vessel. The losses are due to conduction, convection, and radiation. This loss is quantified using equation 4 . However, the radiation loss is very small and is not considered in this paper.

$$
Q_{\text {loss }}=Q_{\text {cond }}+Q_{\text {conv }}+Q_{\text {rad }} \quad \text { eq. } 4
$$

The top and bottom area of the pressure vessel has similar dimensions and their cumulative heat loss is evaluated using equation 5 , where, $\mathrm{V}$ is the average wind speed that causes the convection loss.

$$
\begin{array}{ll}
Q_{\text {top }, \text { bottom }}=\frac{T_{s}-T_{a}}{\left(\frac{1}{h_{w}}+\frac{L}{k A_{t}}+\frac{1}{h_{s} A_{t}}\right)} & \text { eq. } 5 \\
h_{w}=5.7+3.8 \mathrm{~V} & \text { eq. } 6
\end{array}
$$

The sidewall heat loss of the pressure vessel is determined using equation 7.

$$
Q_{l, w a l l}=\left(T_{s}-T_{a}\right) /\left(\frac{1}{h_{w} 2 \pi r_{o} l}+\frac{\ln \left(\frac{r_{o}}{r_{i}}\right)}{2 \pi k}\right) \quad \text { eq. } 7
$$

The cumulative thermal power of the parabolic dish collector and the heat used to sterilize the medical kits were analyzed using equations 8 and 9 respectively.

$$
\begin{array}{ll}
Q_{\text {total }}=Q_{\text {water }}+Q_{\text {steam }}+Q_{\text {req }}+Q_{\text {loss }} & \text { eq. } 8 \\
Q_{u}=Q_{\text {water }}+Q_{\text {steam }}+Q_{\text {req }} & \text { eq. } 9
\end{array}
$$

\subsubsection{Parabolic Dish Concentrator}

The solar collector used in the study is a $2.4 \mathrm{~m}^{2}$ fixed focus parabolic dish concentrate laminated with aluminum foil reflector. The collector has provided with the required thermal power using the available daily solar radiation. The concentration ratio is $63.47 \mathrm{~cm}$, calculated by equation 10 .

$$
c=\frac{A_{a}}{A_{a b s}}=\frac{1}{\sin \theta_{s}{ }^{2}} \quad \text { eq. } 10
$$

\subsection{Modeling and Simulation}

Computational Fluid Dynamics (CFD) is used to simulate the thermal phenomena inside the pressure vessel and see the increasing temperature in sterilizing the medical instruments. In 
addition, ANSYS Fluent 12.1 is used to solve the unsteady fluid flow and heat transfer of the system.

\subsubsection{Mathematical Modeling and Nature of Steam Flow}

Distribution of steam inside the pressure vessel is modeled using CFD. Equation 2 determines the mass flow rate of the steam in pressure vessel. The water in the pressure vessel converts into steam and the volumetric flow rate of steam at 0.3 and 1 bar pressure conditions were calculated using equation 11. Similarly, the expected steam flow velocities in the pressure vessel and its Reynolds number have calculated using equations 12 and 13 respectively. The nature of the steam flow within the pressure vessel is turbulent flow.

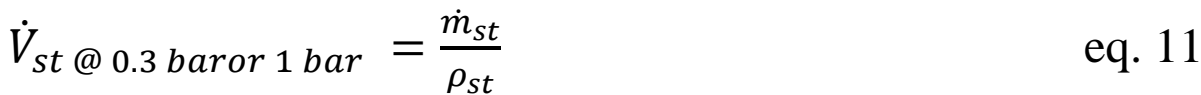

$$
\begin{aligned}
& \dot{u}_{s t} @ 0.3 \text { baror } 1 \text { bar }=\frac{\dot{V}_{s t}}{\dot{A}_{s t}} \quad \text { eq. } 12
\end{aligned}
$$

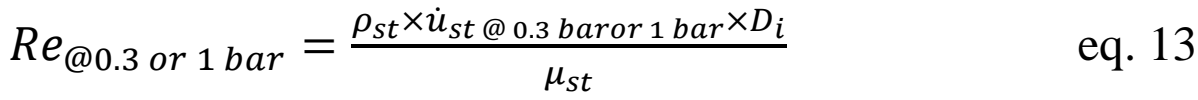

\subsection{Materials Used}

Materials used to develop the test rig include parabolic dish concentrator, pressure vessel, support structure and solar tracking system, data acquisition, support tray and biological tests. The concentrator is a $1.8 \mathrm{~m}$ diameter satellite parabolic dish laminated with high reflective aluminum foil as shown in figure 1. The dish was used to collect the incoming solar rays into the pressure vessel. Table 2 shows the specification of the parabolic dish. The pressure vessel was coated with black paint to absorb more energy. The pressure cooker was of $3 \mathrm{~mm}$ thickness and it is easily available local market. The pressure vessel includes analog temperature meter that can measure up to $150^{\circ} \mathrm{C}$ and pressure gauge on its top to measure the pressure up to four bars. A modified relief valve maintains the steam pressure at one bar that is the optimum pressure for sterilization. The side of the pressure vessel is insulated with a $25 \mathrm{~mm}$ thickness fiberglass insulation to minimize heat loss. Tray was used inside the pressure vessel to hold the equipment to be sterilized and avoid direct contact with the bottom part of the pressure vessel. Figure 1 shows the pressure vessel and its integrated accessories. 


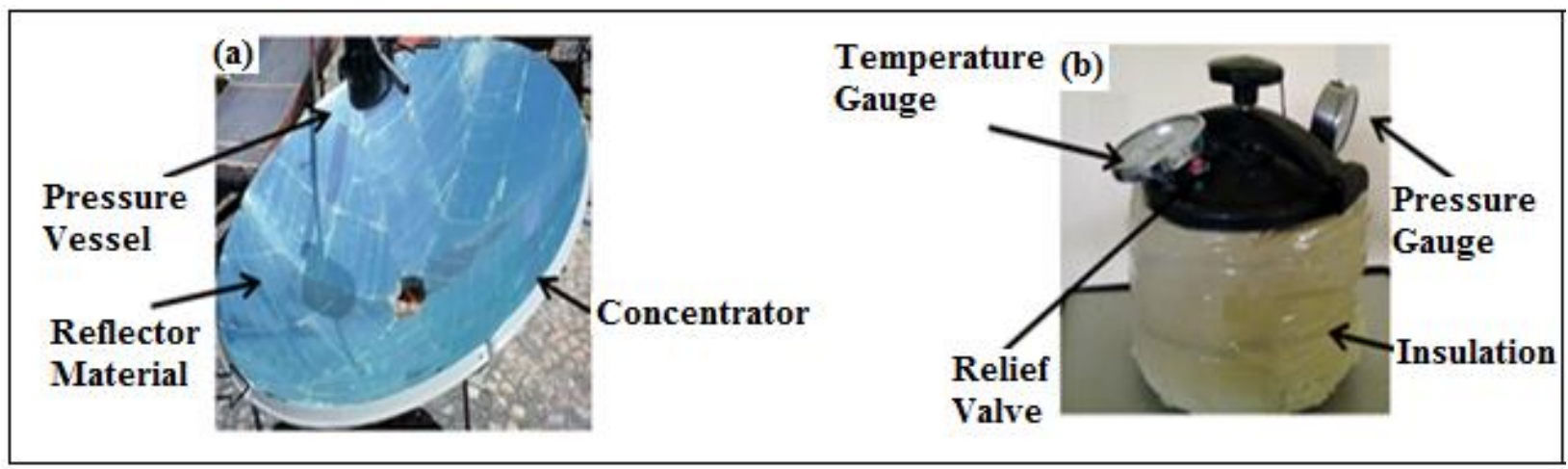

Figure 1. Collector and receiver of the autoclave (a) filmed satellite dish, and (b) pressure vessel.

Table 2. Characteristics of parabolic dish concentrator.

\begin{tabular}{|lll|}
\hline Parameters & Symbol & Value \\
\hline Aperture diameter & $\mathrm{d}_{\mathrm{a}}$ & $1.75 \mathrm{~m}$ \\
\hline Aperture area & $\mathrm{A}_{\mathrm{a}}$ & $2.4 \mathrm{~m}^{2}$ \\
\hline Concentration ratio & $\mathrm{C}$ & 63.47 \\
\hline Focal distance & $\mathrm{f}$ & $0.603 \mathrm{~m}$ \\
\hline Depth of parabolic dish & $\mathrm{h}$ & $0.3 \mathrm{~m}$ \\
\hline
\end{tabular}

Solar concentrators are very sensitive to sudden change in the direction of incoming solar rays and demand at least one axis tracking with manually assisted secondary tracker in order to harness maximum thermal power at the pressure vessel. In the present case, manual tracking system is sufficient to develop the required sterilization temperature and pressure (Fig 2). Temperature development at different points of the pressure vessel and ambient temperature was recorded with the help of a national instrument NIcDAQ - 9172 data logger using K-type thermocouple as a sensor. In addition, WSS-411 analogue temperature gauge was fitted on the top cover of the pressure vessel to measure the temperature development up to $150^{\circ} \mathrm{C}$. The solar radiation was measured by SP LITE pyrometer integrated with a METEON data logger (Fig 2c).
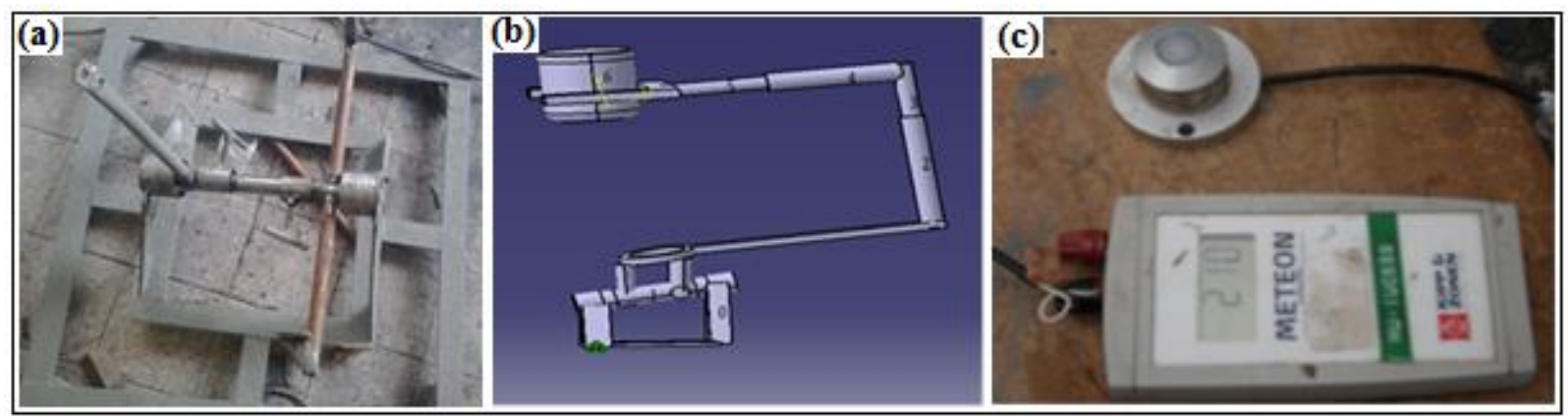

Figure 2. Manual tracking system, (a) actual tracking mechanism, (b) schematic, and (c) SP LITE pyrometer solar radiation sensor and METEON data logger. 
Temperature stripe and biological indicators have used to indicate the effectiveness of the sterilizing process as shown in figure 3 (a) and (b).

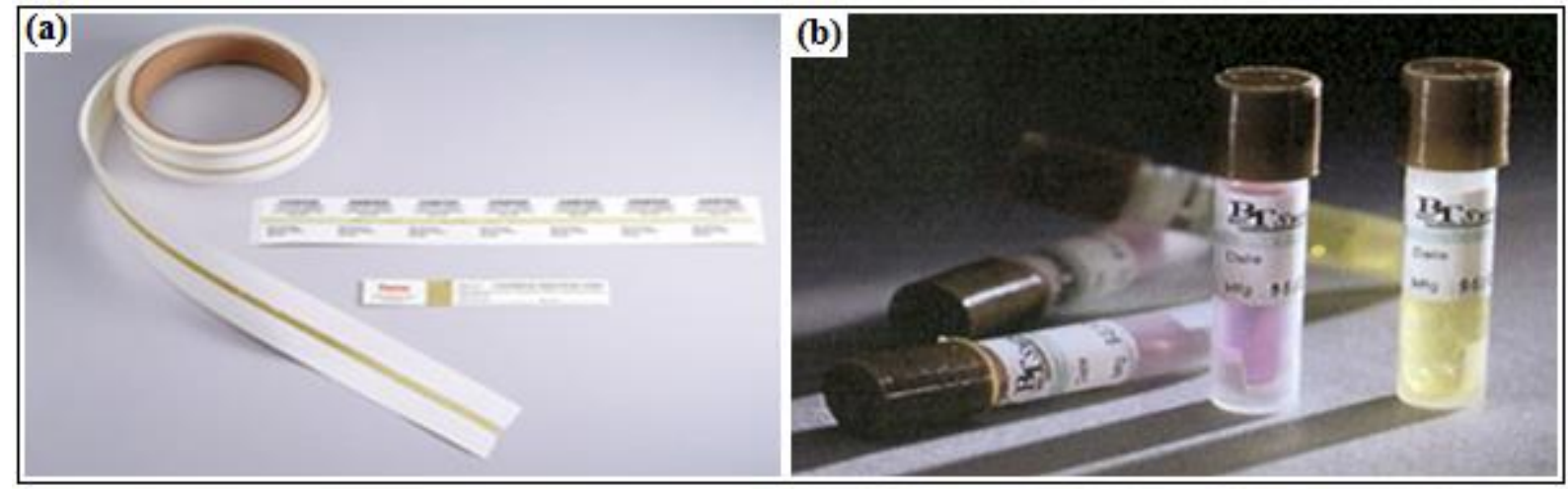

Figure 3. Sterilization effect indicators, (a) temperature stripe, (b) biological indicator.

The test rig shown in figure 4 was installed in a shade free area and the experiment was conducted on clear sky days.

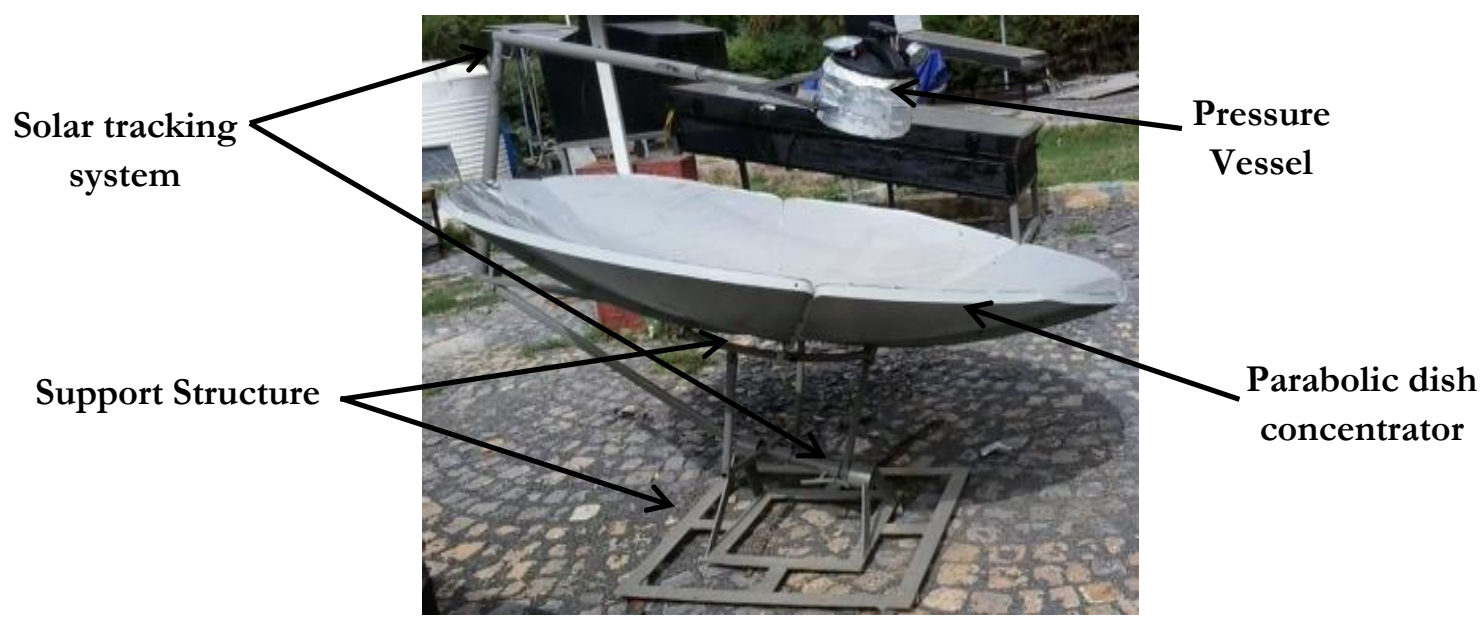

Figure 4. Components of the experimental setup.

\subsection{Experimental Procedure}

During the experiment, $300 \mathrm{ml}$ tap water was used in the pressure vessel and $8 \mathrm{kits}$, considered as one load, of infected medical devices were placed on top of the tray above the tap water inside the pressure vessel. Then, the pressure vessel was placed on the focus of the solar parabolic dish concentrator. Afterwards, the parabolic dish was faced towards the sun and data acquisition has begun to record various measurements. 


\section{RESULTS AND DISCUSSION}

\subsection{Numerical Simulation}

The numerical simulation of this study is considered as two-dimensional unsteady flow inside the pressure vessel. The simulation run for 5400 seconds and in the first 900 seconds, the interior fluid temperature has reached to $370^{\circ} \mathrm{C}$ and at 1800 seconds, it entered to saturation state at a temperature of $412^{\circ} \mathrm{C}$. This indicated that the heat transfer phenomenon in the pressure vessel is stable even at elevated temperature (Fig 5) and the sterilization process at the preset operating pressure is quick.

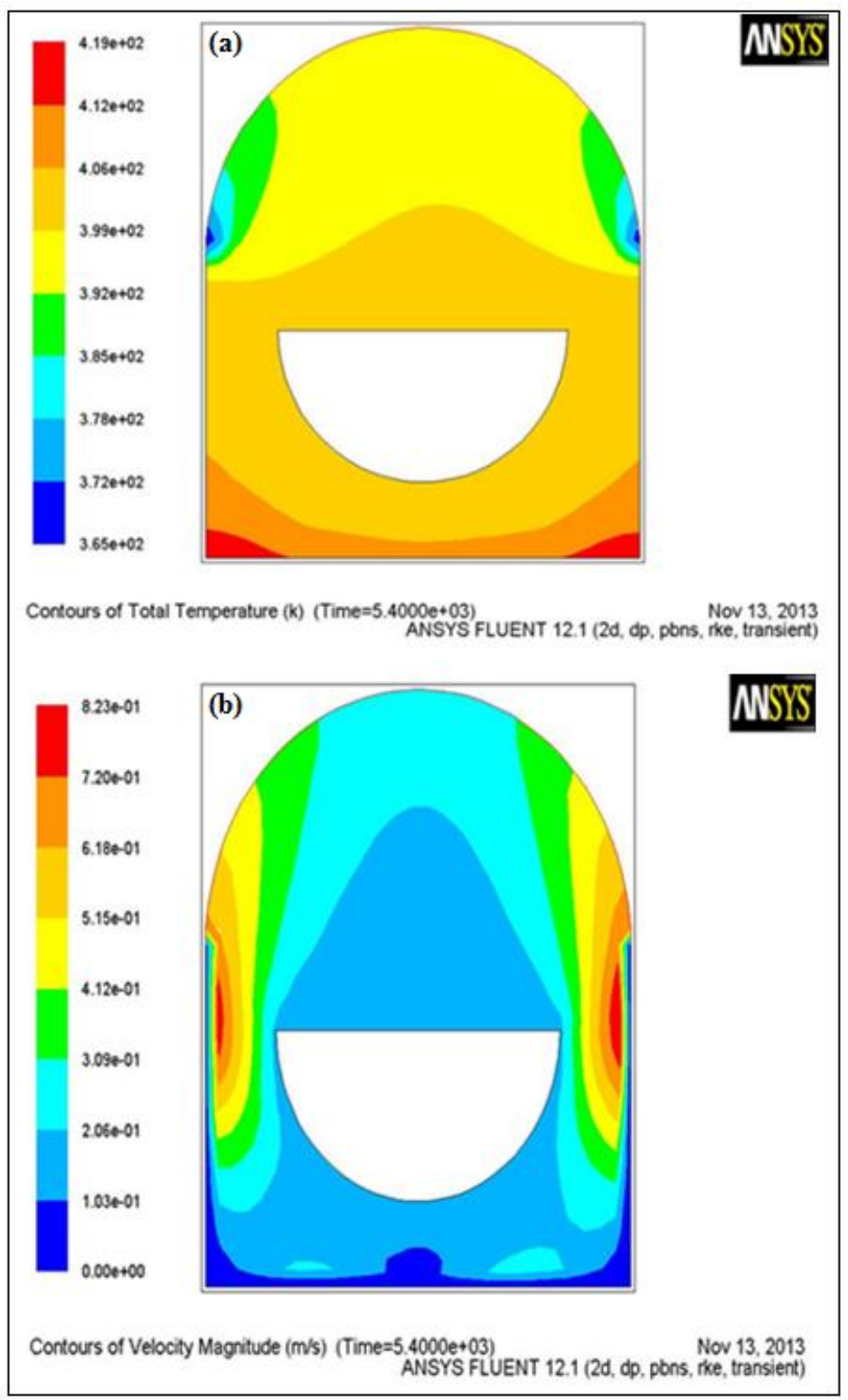

Figure 5. Two-dimensional unsteady flow, (a) temperature contour, and (b) velocity contour. 


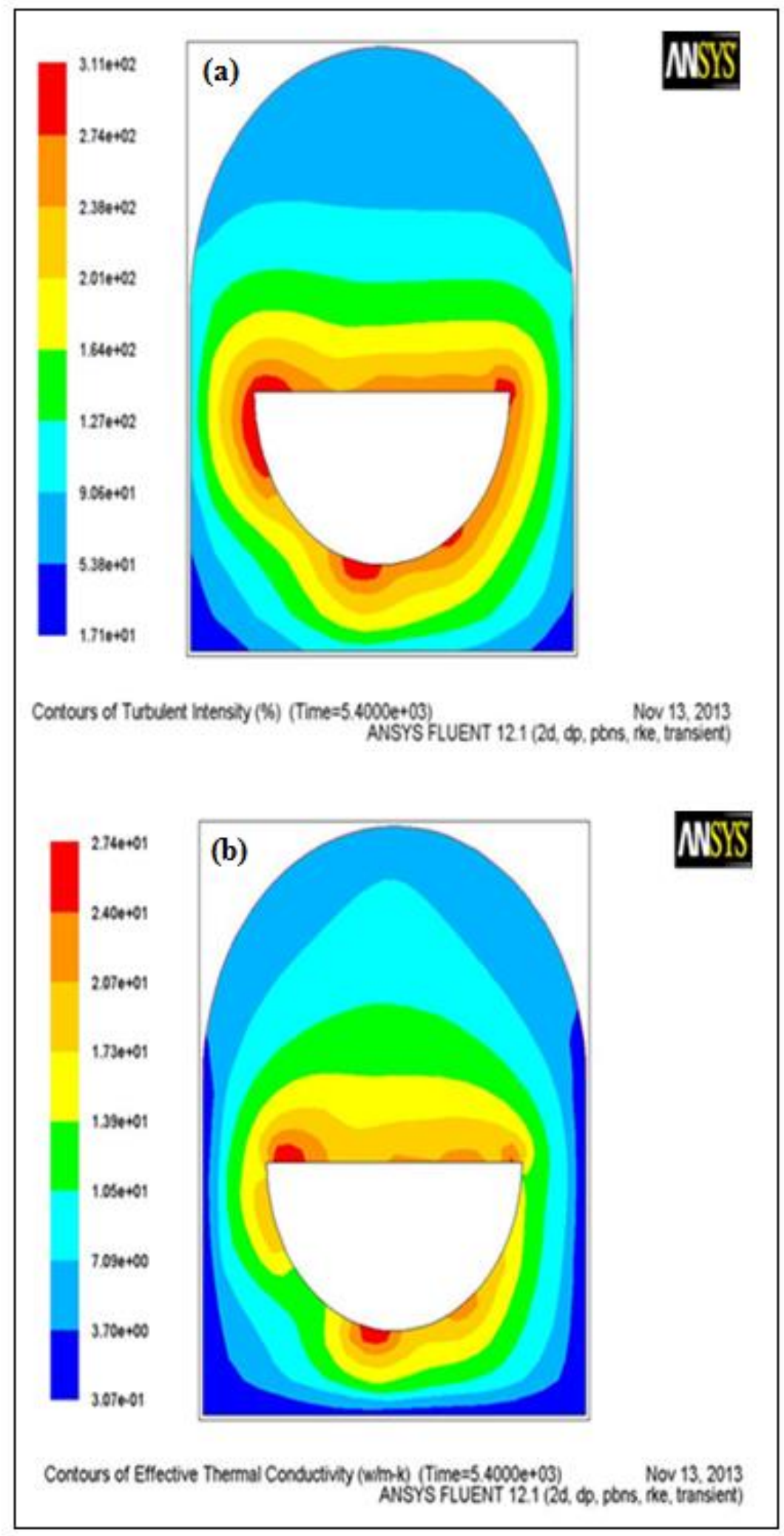

Figure 6. Two-dimensional unsteady flow, (a) turbulence intensity contours, and (b) thermal conductivity contours. 
No slip condition is considered in simulating the fluid flow velocity and temperature contours. This provides the velocity profile normal to the surface as shown in figure 5(b). This indicates that the eddy motion and eddy diffusivities are much higher in the core region of a turbulent boundary layer. However, because of the no-slip condition the eddy motion loses its intensity near to the wall and becomes zero at the wall. Accordingly, the velocity and temperature profiles are nearly uniform at the core region of the turbulent boundary layer, but very steep in the thin layer adjacent to the wall with large velocity and temperature gradients. The simulation further shows development of high turbulence around the sterility package as shown in figure 6a with uniform velocity and temperature profile. Accordingly, the turbulent thermal conductivity that accounts for thermal energy transport by turbulent eddy is high around the sterility package as shown in figure $6 b$.

In general, the simulation result has shown favorable condition for sterilization process by achieving sterilization temperature in short period of time and kept constant until the end of sterilization process compared to actual experimental results. This makes the full sterilization process faster in simulation than actual experimental process as the thermal power required for sterilization depends on the available solar intensity. Besides, heat loses cannot be completely avoided in the actual experiment which results in the sterilization process to occur in much longer time than that of the simulation.

\subsection{Experimental Trial Test Results}

The prototype was run for six experimental successive tests and show repeatable results. The experiment includes both no load and with load conditions.

\subsubsection{No Load Condition}

The no load condition was run three experimental trials without putting any medical appliances to be sterilized using different quantity of water in the pressure vessel.

The first trial considered $600 \mathrm{ml}$ of tap water. Maximum pressure of 0.9 bars obtained and steam temperature of $125^{\circ} \mathrm{C}$ was maintained for 80 minutes (Fig 7a). The maximum and minimum global solar radiation during this experiment was $964 \mathrm{~W} / \mathrm{m}^{2}$ and $816 \mathrm{~W} / \mathrm{m}^{2}$ respectively (Fig $7 \mathrm{~b}$ ). The results show that the solar autoclave is achieved the required sterilization process. 


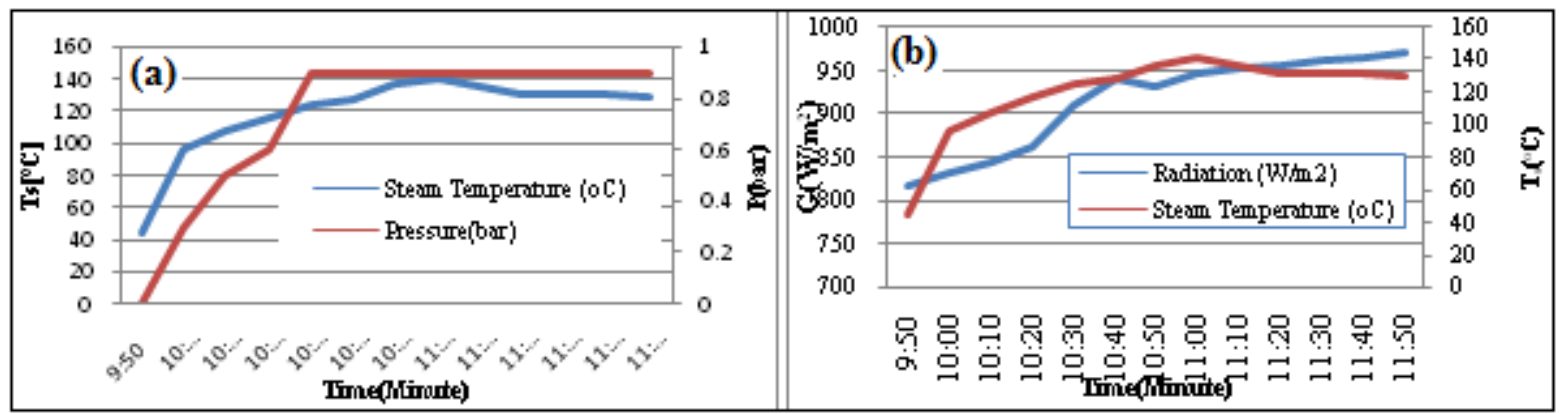

Figure7. No load at $600 \mathrm{ml}$, (a) steam temperature and pressure development, and (b) radiation and steam temperature development.

In the second trial, $800 \mathrm{ml}$ of tap water was used and conducted on the same day as experiment one. As illustrated in figure 8(a), the solar radiation has reached a maximum of $970 \mathrm{~W} / \mathrm{m}^{2}$ and dropped to $400 \mathrm{~W} / \mathrm{m}^{2}$, which affected the sterilizing condition as shown in figure $8(\mathrm{~b})$. This shows that though the system has achieved the sterilization requirement, the steam pressure did not exceed 0.8 bar and the temperature reached a maximum of $124^{\circ} \mathrm{C}$ and kept stable for 40 minutes. This trial showed that the sterilization process took longer time, about 50 minutes, to reach sterilization temperature and pressure.

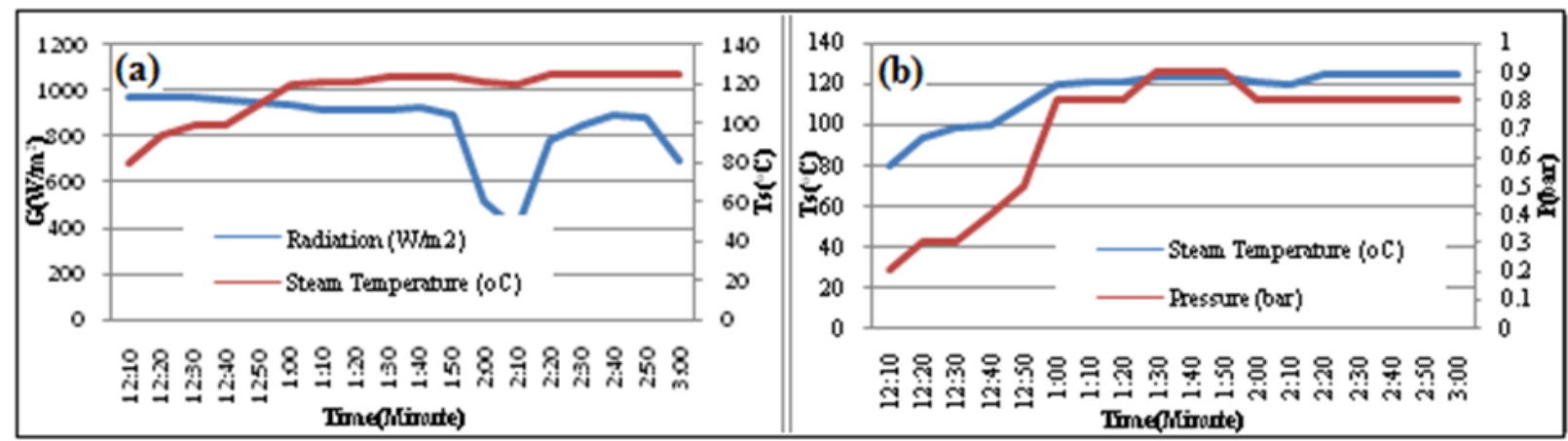

Figure 8. No load condition at $800 \mathrm{ml}$, (a) steam temperature and pressure development, and (b) radiation and steam temperature development.

The experiment conducted with $300 \mathrm{ml}$ of tap water its temperature and pressure development in the system is shown in figure 9. Maximum temperature and pressure achieved are $147^{\circ} \mathrm{C}$ and one bar respectively. During this test, the maximum and minimum global solar radiation was 880 $\mathrm{W} / \mathrm{m}^{2}$ and $705 \mathrm{~W} / \mathrm{m}^{2}$ respectively. This experiment confirms that the designed solar autoclave could give a better result, very close to the standard sterilization temperature and pressure required for disinfecting bacteria's, in the intended rural health centers under the specified (C) CNCS, Mekelle University 
conditions. Sterilization temperature and pressure were recorded continuously during the experiment session. During the test, the steam temperature has shown a continuous increment and reached the preset pressure within 25 minutes. Afterwards, constant temperature and pressure were maintained.

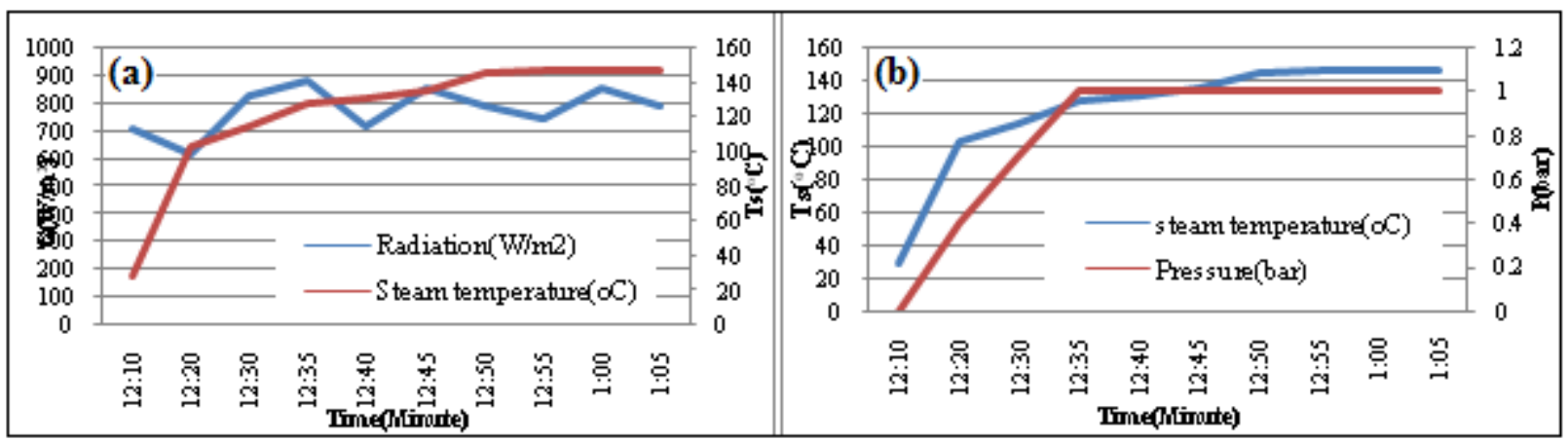

Figure 9. No load condition at $300 \mathrm{ml}$ (a) steam temperature and pressure development and (b) radiation and steam temperature development

\subsubsection{With Load Condition}

In this case, eight different medical appliances were loaded on a 300ml tap water loaded pressure vessel. Figure 10a shows the mode of loading in the pressure vessel. Indicator tape was used to indicate steam temperature and pressure distribution inside the pressure vessel. Thermocouples were used to measure the steam temperature development during sterilization process and observe the equivalent pressure as shown in figure $10 \mathrm{~b}$.
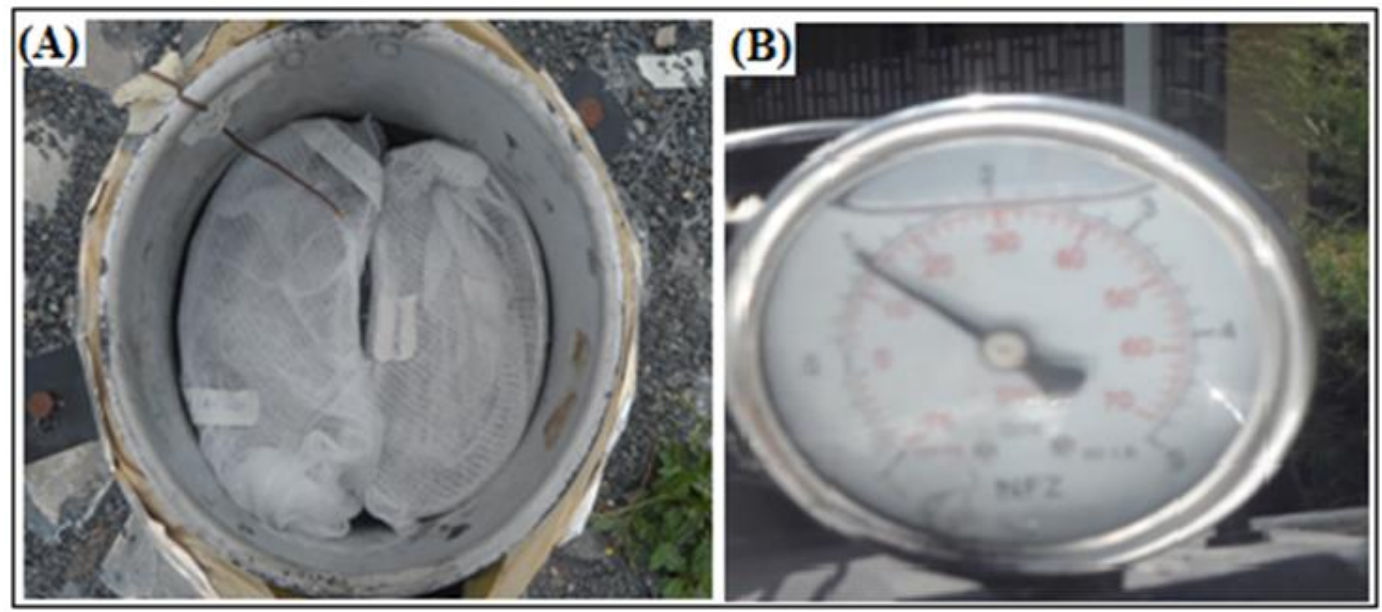

Figure 10.Way of appliance loading and associated pressure. 
The experiment was run for 55 minutes. In the first 40 minutes, both steam temperature and pressure have linearly increased until they reached $147^{\circ} \mathrm{C}$ and one bar respectively. These values were maintained for 15 minutes (Fig 11b) in which the sterilization process was undertaken. After 50 minutes, the steam in the pressure vessel was evaporated and gone through the relief valve. This resulted in the decrease of pressure, which finally reduced to zero within 10 minutes (Fig 11b) the period is called drying period.

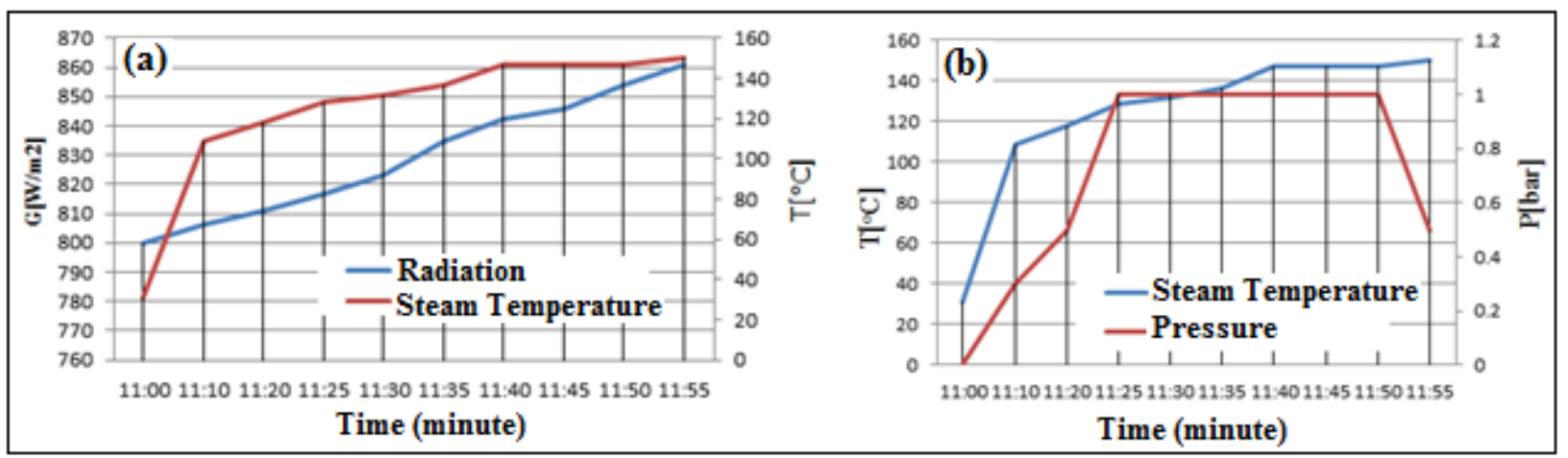

Figure11.With load condition steam temperature and pressure development.

\subsection{Monitoring Sterilization Process}

The sterilization procedures have monitored through a combination of validation techniques such as mechanical, chemical, and biological techniques.

\subsubsection{Mechanical Validation Techniques}

The mechanical validation technique includes assessment of the cycle time, temperature, and pressure of sterilization equipment by observing the gauges (Fig 11b). The results confirm that all mechanical tests have yielded positive results (Table 3).

Table 3. Mechanical validation result for the above experiment results.

\begin{tabular}{|lll|}
\hline No & Validation Criteria & Status \\
\hline 1 & Enough power supply & Fulfilled \\
\hline 2 & Temperature control & Fulfilled \\
\hline 3 & Pressure control & Fulfilled \\
\hline 4 & Steam leakage & No leakage \\
\hline 5 & Water leakage & No leakage \\
\hline 6 & Temperature specification & Fulfilled \\
\hline 7 & Pressure specification & Fulfilled \\
\hline 8 & Thermometric test & Fulfilled \\
\hline
\end{tabular}




\subsubsection{Chemical Validation}

This validation technique uses sensitive chemicals to assess the physical conditions such as temperature during the sterilization process. Chemical indicator, the heat sensitive tape, shows color change rapidly when a given parameter is reached or achieved. An internal chemical indicator was placed in every sterilization package to ensure that the sterilization agent has penetrated the packaging material and reached inside surface of the instruments. An external indicator have used when the internal indicator could not be seen from the outside package. Autoclave indicator tape can provide a more reliable indication if the sterilization conditions are met. The validation technique, the color change, proved successful for sterilization process (Fig 12b). The date specified in the indicator is based on Ethiopian calendar.

\subsubsection{Biological Validation}

This validation technique is the most acceptable sterilization validation technique because it directly determines the availability of microorganisms such as Geobacillus or Bacillus species. Because of the spores used as biological indicators (BI), they are more resistant and present in greater numbers than the common microbial contaminants found on patient care equipment. Inactivated BI indicates that other potential pathogens in the load are killed (Fig12a).

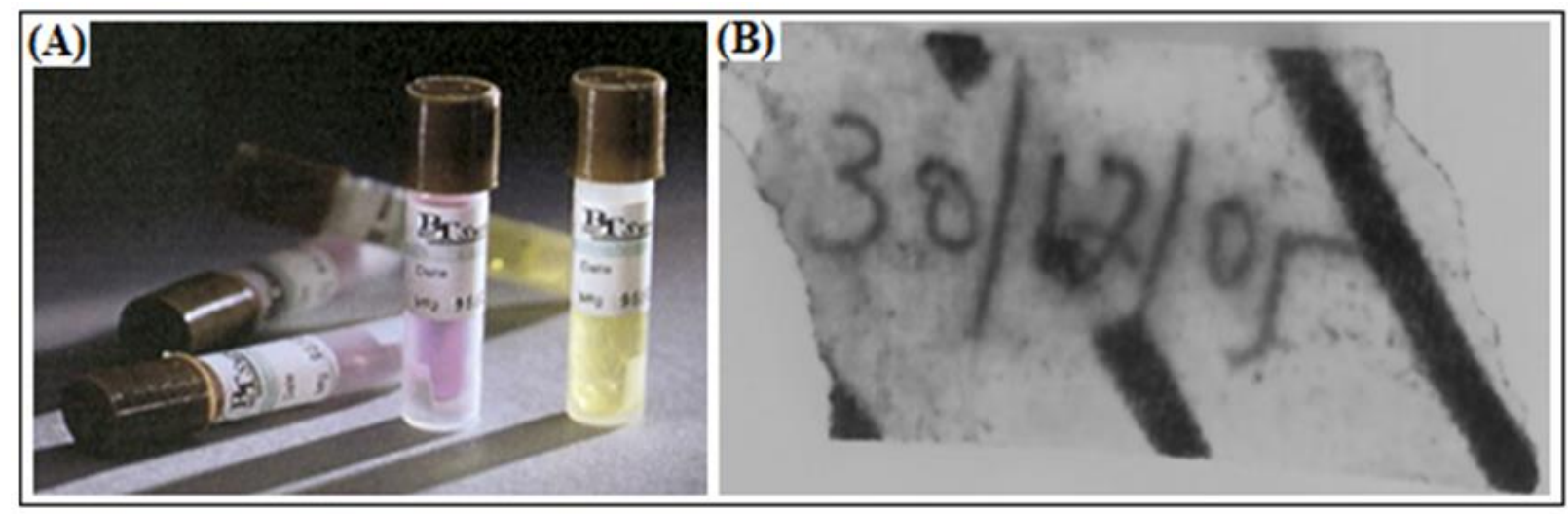

Figure 12. Biological validation, (a) biological indicator, (b) indicator tapes color change after sterilization.

A $3 \mathrm{M}^{\mathrm{TM}}$ autoclave-steam indicator tape is used to identify the sterilization process. A color change in the indicator stripes verified the condition necessary for steam sterilization. The tape was initially a buff colored crepe paper, with diagonal white indicator stripes. These strips were turned to dark brown after exposure to the saturated steam with a particular temperature and time 
(Fig 12b). This validation mechanism has confirmed that the sterilization performed is adequate. The experimental results thus have shown that the developed solar autoclave has passed the validation-monitoring test and proved successful for sterilization of infected medical equipment. After the successful experimental tests undertaken in the university, the setup was taken to Hintalo Wejerat Hagereselam health post, one of the off grid rural health post in southern Tigray, for further community trial. Similar results were achieved in the health post and the end users have given an encouraging feedback particularly on the system's simplicity in the design, operation, affordability and effective technology. The systems proved effective for the off grid rural areas.

\section{CONCLUSION}

Proper sterilization of reusable medical devices and surgical instruments are critical aspects of modern health care delivery system and directly affects patient safety. This paper has tried to provide a suitable solar-based sterilizing system that can work efficiently in areas where there is no access to electricity. The "no-load" and "with-load" experiments have demonstrated the effectiveness of the technology and the simulation has provided good results that are ideal. The experimental and field test results of the prototype shows the potential of the system for dissemination.

\section{ACKNOWLEDGEMENTS}

The authors are grateful to the Norwegian government support of development program (EnPe-I Project) for the financial support to conduct the research work.

\section{REFERENCE}

Block, S. 2001. Disinfection, Sterilization, and Preservation. $5^{\text {th }}$ edition, ISBN: 0683307401 9780683307405, Lippincott Williams \& Wilkins, 1481p.

Dravid, M.N., Chandak, A., Phute, S.U., Khadse, R.K., Adchitre, H.R \& Kulkarni, S.D. 2012. The Healthcare in Ethiopia, http://www.moh.gov.et/; http://www.ethiomedic.com/.

Heuck, C. C \& Deom, A. 1991. Health Care in the Developing World: Need for Appropriate Laboratory Technology. Clinical Chemistry, 37(4):490-496.

FMoH, 2010. http://www.moh.gov.et/tigrayhb. 
Oara Neumann, Curtis Feronti, Albert D. Neumann, Anjie Dong, Kevin Schell, Benjamin Lu, Eric Kim, Mary Quinn, Shea Thompson, Nathaniel Grady, Peter Nordlander, Maria Oden \& Naomi J. H. 2013. Compact solar autoclave based on steam generation using broadband light-harvesting nanoparticles. National Academy of Sciences, special series of Inaugural Articles, 110(29): 11677-11681 (https://doi.org/10.1073/pnas.1310131110).

Samuel Tesema \& Getachew Bekele. 2014. Resource Assessment and Optimization Study of Efficient Type Hybrid Power System for Electrification of Rural District in Ethiopia. International Journal of Energy and Power Engineering, 3(6): 331-340.

Trabia, S. S. 2012. The Design and Testing of a Solar Autoclave with Broad Spectrum Sterilization Capabilities- The use of solar energy for powering a portable autoclave. Journal of Hospital Infection, 80: 345-347. 